DOI 10. 18307/2021. 0228

(c) 2021 by Journal of Lake Sciences

\title{
东太湖围网拆除前后水生植被群落遥感监测及变化
}

\author{
杨井志成 ${ }^{1,2}$, 罗菊花 ${ }^{1 * *}$, 陆莉蓉 ${ }^{1,2}$, 孙 喆 $^{1,2}$, 曹志刚 ${ }^{1,2}$, 曾庆飞 ${ }^{1}$, 毛志刚 ${ }^{1}$ \\ (1: 中国科学院南京地理与湖泊研究所流域地理学重点实验室,南京 210008) \\ (2:中国科学院大学, 北京 100049)
}

\begin{abstract}
摘 要: 为削减东太湖养殖污染, 改善湖泊水质, 苏州市于 2018 年底基本完成东太湖养殖围网拆除工作. 围网拆除后, 湖 泊生态环境对此如何响应, 已成为学者及相关管理部门关注的重点. 水生植被在维持湖泊生态系统平衡、物质循环和净 化水质方面发挥着重要的作用, 是诊断湖泊生态系统健康状态的关键指标. 本研究基于 Sentinel-2 卫星数据, 利用分类决 策树模型和基于生活史的沉水植被优势种群提取方法, 监测了东太湖 2017 年 (围网拆除前) 和 2019 年 (围网拆除后) 的 水生植被类群和沉水植被优势种群的空间分布. 经验证, 水生植被类群监测精度为 $82.66 \%$, Kappa 系数为 0.77 ; 沉水植被 优势种群的监测精度为 $62.08 \%$,Kappa 系数为 0.56 . 结果表明: 围网拆除后, 东太湖水生植被优势类群由围网拆除前的沉 水植被转变为浮叶植被;沉水植被分布面积减少,且种群由优势度相差不大的七大优势种群逐步向蕰草和伊乐藻占据绝 对优势发展,逐渐趋于单一化.
\end{abstract}

关键词: 东太湖;水生植被;沉水植被; 围网养殖;遥感

\section{Changes in aquatic vegetation communities based on satellite images before and after pen aquaculture removal in East Lake Taihu*}

\author{
Yang Jingzhicheng ${ }^{1,2}$, Luo Juhua ${ }^{1 * *}$, Lu Lirong ${ }^{1,2}$, Sun Zhe ${ }^{1,2}$, Cao Zhigang ${ }^{1,2}$, Zeng Qingfei ${ }^{1}$ \& \\ Mao Zhigang ${ }^{1}$ \\ (1: Key Laboratory of Watershed Geographic Sciences, Nanjing Institute of Geography and Limnology, Chinese Academy of \\ Sciences, Nanjing 210008, P.R.China) \\ (2: University of Chinese Academy of Sciences, Beijing 100049, P.R.China)
}

\begin{abstract}
To improve water quality and enhance ecological management, all the net-pen aquaculture facilities in the East Lake Taihu have been removed by the end of 2018. Understanding the impact of this activity on lake ecosystem health is critical to promote efficient ecological management. Aquatic vegetation, especially submerged aquatic vegetation is an essential component of healthy lake ecosystem, as they provide food and shelter, help to secure and stabilize shorelines and modulate nutrient circulation. Additionally, submerged aquatic vegetation can improve water clarity by competing for nutrient with algae. Monitoring submerged aquatic vegetation is fundamental to lake ecosystem health evaluation. In this study, we leverage Sentinel-2 data to map the temporal change of different types of aquatic vegetation types (i.e., emergent vegetation, floating-leaved vegetation and submerged aquatic vegetation), as well as the dominant submerged aquatic vegetation species. We found that the dominant vegetation shifted from submerged to floating-leaved vegetation after the pen aquaculture removal in East Lake Taihu. Meanwhile, the total coverage of submerged aquatic vegetation and its diversity significantly decreased, suggesting environmental degradation in this area. Our research indicated that removing net-pen culture has negative effect on lake ecosystem health. Efficient ecological management of this critical lake system requires comprehensive evaluation before they implement any management activities.
\end{abstract}

Keywords: East Lake Taihu; aquatic vegetation; submerged vegetation; net-pen aquaculture; remote sensing

* 2020-09-24 收稿; 2020-12-17 收修改稿.

国家自然科学基金项目 (41971314) 和江苏省太湖水环境综合治理课题( TH2019302, TH2018303)联合资助.

** 通信作者; E-mail: jhluo@ niglas.ac.cn. 
以网围养殖为主的养殖渔业是我国淡水渔业发展的一个重要生长点, 自从 1980s 在浅水湖泊中普遍开 展生产性网围养殖以来, 取得了极其显著的经济效益和社会效益 ${ }^{[1]}$. 然而, 由于社会经济的迅速发展, 水资 源利用程度越来越高, 围网养殖规模逐渐增大, 超密度围网养殖成为湖泊水资源过度开发利用的主要方 面 $^{[2]}$. 由于长期人工投喂饵药, 围网内残饵和排泄物剧增, 且围网具有阻滞水流等物理障碍效应及养殖污染 的叠加效应, 长时间、超密度围网养殖可能导致湖泊富营养化、水质恶化以及沼泽化 ${ }^{[2-3]}$. 因此, 为了湖泊生 态的保护和恢复, 有关部门逐步对多个湖泊实施围网拆除行动, 如苏州市于 2018 年初开始对东太湖养殖围 网进行拆除, 至 2018 年底基本完成东太湖养殖围网拆除工作.

围网拆除行动实施后, 学者们开始关注其对湖泊水环境及生态系统的后续影响, 如 Luo 等 $^{[4]}$ 通过布点 取样调查, 对阳澄湖围网拆除前后的水质参数进行了比较分析, 发现围网拆除后, 阳澄湖水质有了明显的提 升; 薛俊增等 ${ }^{[5]}$ 通过设置监测断面, 对淀山湖围网拆除前后的浮游生物开展了调查和分析, 发现围网拆除 后, 淀山湖浮游生物优势种类呈现隐藻一蓝藻型趋势, 表明水质并未有明显改善; 袁林等 ${ }^{[6]}$ 通过实地取样, 对 阳澄湖围网拆除前后浮游甲壳动物群落结构变化进行了调查研究, 发现围网拆除后浮游甲壳动物群落结构 变化不大. 然而, 目前大多研究主要关注围网拆除前后浮游生物生态和水质的变化情况, 较少关注湖泊水生 植被类群和种群的变化.

水生植被, 尤其是沉水植被具有吸附净化、阻滞水流、促进沉降、澄清水质、抑制藻类等生态功能, 在维 持湖泊生态系统平衡、物质循环和水质方面发挥着重要的作用 ${ }^{[7]}$. 开展围网拆除前后水生植被类群 (挺水、 浮叶和沉水植被) 与沉水植被优势种群的调查与研究, 对东太湖后期生态环境评估、管控和修复具有十分重 要的意义. 传统的水生植被监测方法主要是人工调查法, 该方法精度虽高, 但费时、费力, 监测范围小, 时空 连续性较差 ${ }^{[8-10]}$. 遥感技术具有经济性、时效性、综合性、大面积同步观测及历史追溯性等特点, 已成为浅水 湖泊水生植被监测的有效手段 ${ }^{[8]}$. 在湖泊水生植被类群遥感监测方面, 国内外学者构建了一系列用于识别 水生植被类群与蓝藻水华的光谱指数,如归一化植被指数 (normalized difference vegetation index, NDVI) ${ }^{[9]}$ 、 植被出现频率指数 (vegetation prescience frequency, $V P F)^{[10]}$ 、浮叶植被敏感光谱指数 (floating leaf vegetation sensitive index, FVSI ${ }^{[11-12]}$ 、浮游藻类指数 (floating algae index, $\left.F A I\right)^{[13]}$ 和沉水植被敏感光谱指数( submerged vegetation sensitive index, SVSI $)^{[9]}$ 等. 而在沉水植被优势种群的遥感监测方面, 由于沉水植被生长在水面之 下,其本身光谱信号较弱且不同优势种群间光谱差异相对较小, 仅仅利用光谱信息很难对沉水植被不同优 势种群进一步识别和区分. 但由于沉水植被不同优势种群间的生活史存在差异, 因此在一定时间段内, 遥感 监测到的沉水植被只能是某种或某几种当季优势种群, 这就为沉水植被优势种群的时空分布监测提供了新 的可能.

本研究基于高时空分辨率的 Sentinel-2 系列卫星数据, 分析东太湖不同地物的光谱特征, 篮选和构建了 东太湖挺水、浮叶和沉水植被和蓝藻水华的敏感光谱指数, 建立水生植被类群和藻华的分类决策树; 并结合 不同沉水植被优势种群的生活史差异, 提出基于生活史的沉水植被优势种群遥感监测方法. 最后, 对东太湖 围网拆除前后, 水生植被类群和沉水植被优势种群的空间分布及变化进行了监测和分析, 以期为东太湖后 续的水生植被管控和生态修复提供科学依据.

\section{1 研究方法}

\section{1 研究区概况}

东太湖位于太湖东南隅 $\left(30^{\circ} 58^{\prime} \sim 31^{\circ} 07^{\prime} \mathrm{N}, 120^{\circ} 25^{\prime} \sim 120^{\circ} 35^{\prime} \mathrm{E}\right)$, 与西太湖之间以狭窄的湖面相通, 总长 度 $27.5 \mathrm{~km}$, 最大宽度 $9.0 \mathrm{~km}$, 总面积 $131 \mathrm{~km}^{2}$, 年平均水深约 $1 \mathrm{~m}$, 根据中国科学院太湖湖泊生态系统研究站 的长期定点观测, 东太湖年平均水位为 $(1.47 \pm 0.40) \mathrm{m}$, 总磷、总氮指标浓度为 $\mathrm{III} \sim \mathrm{IV}$ 类 $^{[1,14]}$. 围网养殖区主要 集中分布在东太湖的北部、东南角的新开路港附近和西南角的艾白港附近 (图 1a).

根据近几年野外调查和文献记载, 东太湖水生植被主要有三大类群: 浮叶植被、挺水植被和沉水植 被 ${ }^{[15]}$. 其中, 挺水植被主要分布在近岸区, 优势种群为芦苇 (Phragmites communis); 浮叶植被优势种群为荇 菜(Nymphoides peltatum) 和菱角 (Trapa bispinosa) 等; 沉水植被有七大优势种群, 分别是: 菹草 (Potamogeton crispus)、伊乐藻 (Elodea nuttallii)、狐尾藻(Myriophyllum spicatum) 、微齿眼子菜 (P. maackianus)、金鱼藻 (Cer- 


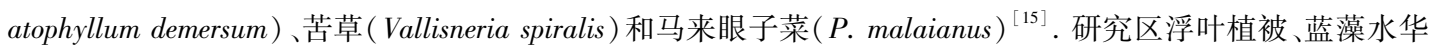
和沉水植被的现场实拍图见图 $1 \mathrm{~b} \sim \mathrm{d}$.
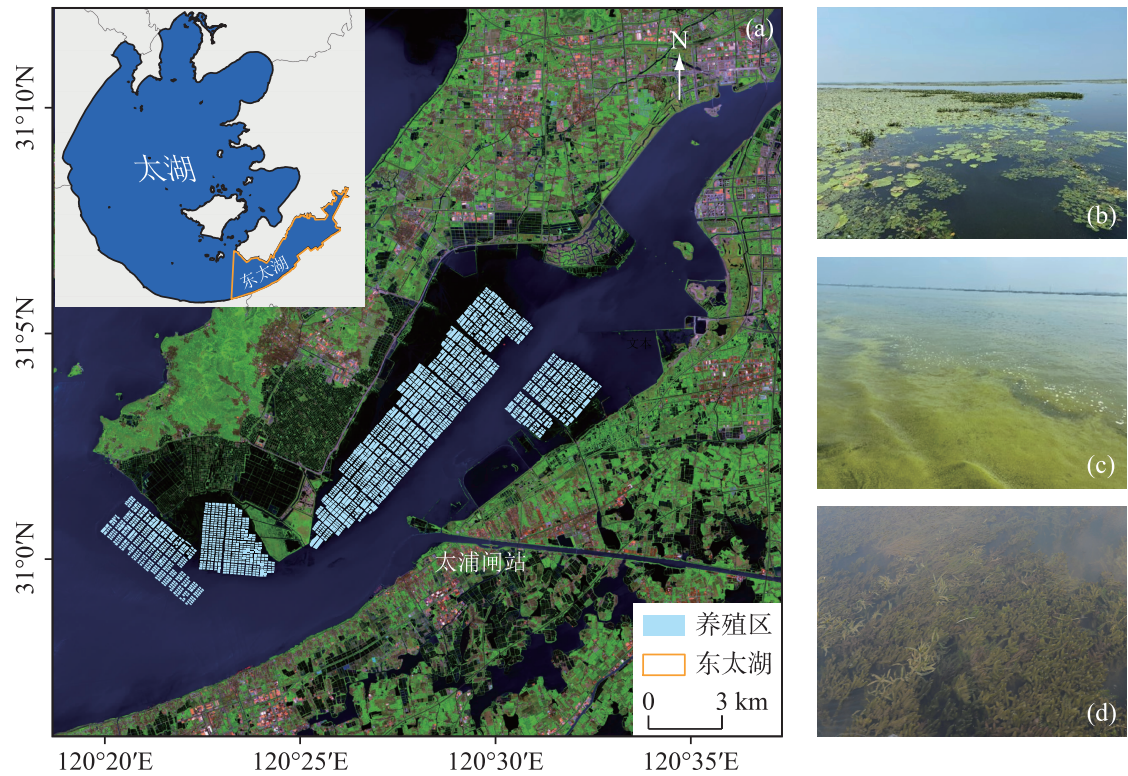

图 1 研究区 Sentinel-2 假彩色影像 (a); 浮叶植被 (b)、蓝藻水华 (c) 和沉水植被 (d) 的现场实拍图

Fig.1 Sentinel-2 false color image of the study area (a); site photos of floating-leaved aquatic vegetation (b), cyanobacteria blooms (c) and submerged vegetation (d)

\section{2 遥感数据源及预处理}

本研究选取 Sentinel-2 系列卫星作为遥感数据源, 该系列包含 Sentinel-2A 和 Sentinel-2B 两颗卫星, 分别 于 2015 年 6 月 23 日和 2017 年 3 月 7 日发射升空,一颗卫星的重访周期为 10 天, 两颗互补后重访周期为 5

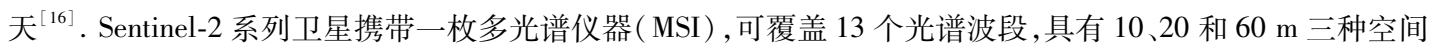
分辨率(表 1). Sentinel-2 MSI 数据来源于欧空局 (https://scihub.copernicus.eu/), 本研究共获取东太湖 2017 和 2019 年质量较高的 16 景 L1C 级影像 (表 1). 本研究采用 Sen2cor 模型对 L1C 级数据进行大气校正,得到 $\mathrm{L} 2 \mathrm{~A}$ 级数据, 并选取 $10 \mathrm{~m}$ 和 $20 \mathrm{~m}$ 的波段数据作为数据源, 在 SNAP 软件中将分辨率为 $10 \mathrm{~m}$ 和 $20 \mathrm{~m}$ 的 L $2 \mathrm{~A}$ 级波段数据重采样至 $10 \mathrm{~m}$,最后对重采样后的数据进行波段合成与裁剪.

表 1 获取 Sentinel-2 影像基本信息

Tab.1 Basic information of Sentinel-2 images used in this study

\begin{tabular}{cc}
\hline 时间 & 影像获取时间 (月-日) \\
\hline 2017 年 & $01-29 、 02-28 、 04-29 、 05-29 、 07-28 、 08-17 、 10-31 、 12-28$ \\
2019 年 & $01-24 、 03-20 、 04-09 、 05-04 、 07-23 、 08-17 、 10-16 、 12-15$ \\
\hline
\end{tabular}

\section{3 野外调查数据获取}

基于研究区水生植被的生长特性,并结合卫星遥感影像过境时间, 本研究于 2017 年和 2019 年 3 月、5 月、7 月、8 月和 9 月分别对研究区水生植被开展野外调查, 共获取了 354 个调查样区 ( 2017 年 153 个, 2019 年 201 个). 考虑到 Sentinel-2 影像的像元大小 $(10 \mathrm{~m})$ 及几何畸变, 每个水生植被调查样区约 $15 \mathrm{~m} \times 15 \mathrm{~m}$, 调 查内容包括水生植被类群、种群、植被覆盖度、经纬度和现场照片等, 用手持 GPS 接收机在样区的中心位置 记录经纬度, 误差约为 $3 \mathrm{~m}$. 为使得样区信息与遥感影像的解译能力和空间分辨率相匹配, 获取野外信息后, 对数据进行再处理, 得到样区的优势类群和种群, 具体处理如下: 当样区内存在多个类群时, 以覆盖度最大 
的类群作为该样区的优势类群; 当样区水生植被优势类群为沉水植被时, 以覆盖度最大的沉水植被优势种 群作为该样区的优势种群.

\section{4 水生植被类群和藻华提取方法}

本研究基于分类决策树 (图 2a) 对东太湖水生植被类群和藻华进行提取,所用指数为:挺水植被敏感指 数 (emergent vegetation sensitive index, EVSI)、藻类指数 (algae index, $A I)$ 、归一化植被指数 $(N D V I)$ 和沉水植 被敏感指数 $(S V S I)$.

表 2 不同指数计算公式*

Tab.2 Formulas of different indexes

\begin{tabular}{cc}
\hline 指数名称 & 计算公式 \\
\hline$E V S I$ & $E V S I=\frac{\mathrm{B} 8 \mathrm{a}-\mathrm{B} 4}{\mathrm{~B} 8 \mathrm{a}+\mathrm{B} 4}$ \\
$A I$ & $A I=\mathrm{B} 3-\frac{\mathrm{B} 2+\mathrm{B} 4}{2}$ \\
$N D V I$ & $N D V I=\frac{\mathrm{B} 8-\mathrm{B} 4}{\mathrm{~B} 8+\mathrm{B} 4}$ \\
$S V S I$ & $S V S I=T C_{1}-T C_{2}$ \\
\hline
\end{tabular}

* B2: 蓝波段; B3: 绿波段; B4: 红波段; $\mathrm{B} 8$ ：近红外波段; B8a：窄近红外波段;

$T C_{1}$ : 亮度指数; $T C_{2}$ : 绿度指数.
据图 2(b) 所示, 挺水植被在近红外区间反射率远高于其它 地物, 且在 B 8 a 波段反射率最高, 在 B4 波段反射率最低; 浮叶植 被具有典型的植被光谱特征,近红外区间的反射率大于开阔水 面; 沉水植被整体反射率较低, 植被光谱特征不明显, 但利用缨 帽变换后的土壤亮度指数与绿度指数的差值能较好的识别沉水 植被 ${ }^{[15]}$. 蓝藻水华和浮叶植被的光谱特征相似, 但蓝藻水华在 B3 波段处反射率更高, 形成典型的叶绿素反射峰 ${ }^{[17]}$. 因此, 本 研究基于上述敏感光谱特征, 对 B8a 波段和 B4 波段进行归一化 处理构建了 $E V S I$, 用于提取挺水植被, 并篮选了 NDVI、SVSI 和 $A I$ 分别用于提取浮叶植被、沉水植被和蓝藻水华 (表 2).

挺水植被、浮叶植被、蓝藻水华和开阔水面在不同的敏感指 数上均有明显的差异可分性. $E V S I>0.5$ 时, 只存在挺水植被的 频率单峰 (图 2c); $A I>350$ 时, 只存在蓝藻水华的频率单峰 (图 $2 \mathrm{~d}) ; N D V I>0.4$ 时, 只存在浮叶植被的频率单峰(图 $2 \mathrm{e}$ ); $S V S I<$ 2400 时, 只存在沉水植被的频率单峰(图 2f). 根据各类地物指数敏感阈值, 建立并执行分类决策树 (图 2a), 获取水生植被类群和藻华的空间分布.
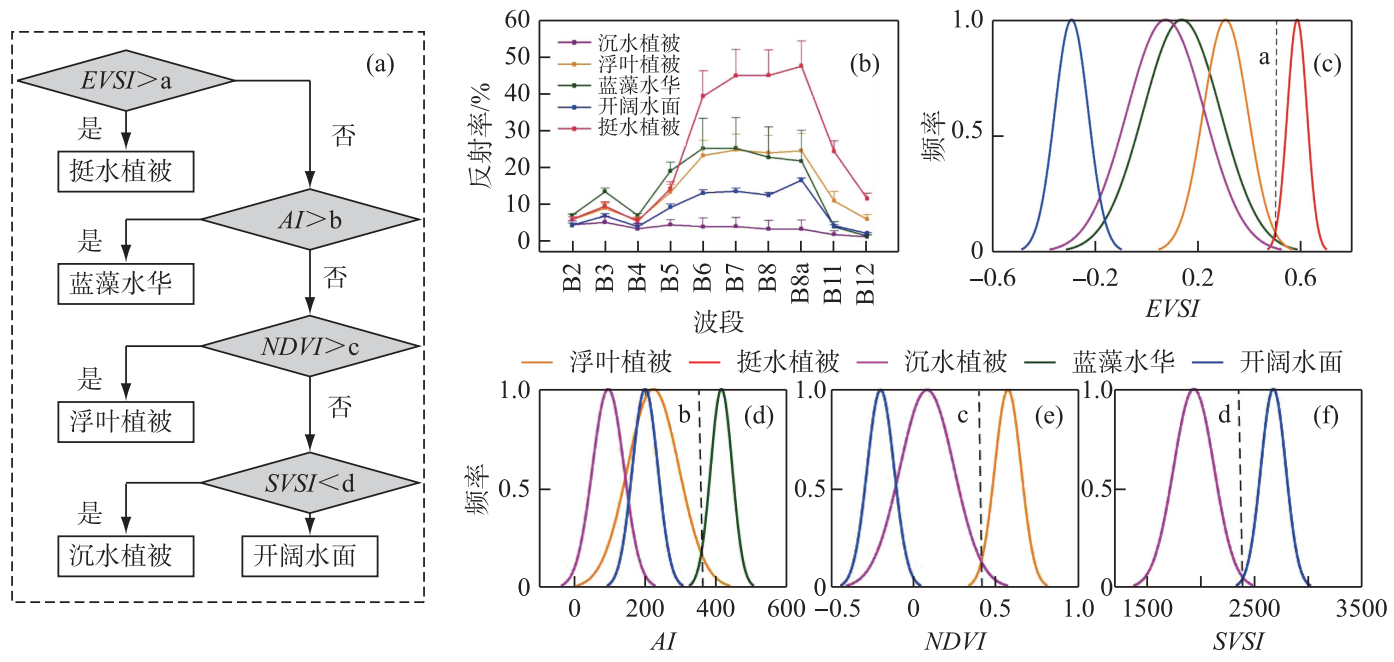

图 2 水生植被类群和藻华的分类决策树 ( a ) ; 分类地物平均光谱曲线 (b); $\operatorname{EVSI}(\mathrm{c}) 、 A I(\mathrm{~d}) 、$ $N D V I(\mathrm{e})$ 和 $S V S I(\mathrm{f})$ 指数的归一化频率直方图

Fig. 2 Classification decision tree of aquatic vegetation types and cyanobacteria blooms (a); Mean spectral curves of classification features (b) ; Normalized frequency histogram of EVSI (c), AI (d), NDVI (e) and SVSI (f)

\section{5 沉水植被优势种群提取方法}

本研究利用基于生活史的沉水植被优势种群提取方法 ${ }^{[15]}$, 对东太湖沉水植被的 7 大优势种群进行了空 间分布监测,具体提取原理及方法见表 3 . 
表 3 基于生活史的沉水植被优势种群提取原理及方法

Tab.3 Principle and method of extracting different submerged vegetation species based on living history

\begin{tabular}{|c|c|c|}
\hline 优势种群 & 生活史 & 提取原理及方法 \\
\hline 菹草 & $\begin{array}{l}\text { 菹草较为耐寒, 能够忍受 } 0^{\circ} \mathrm{C} \text { 以下的寒冷, } 3- \\
4 \text { 月生长速度较快, } 4 \text { 月下旬至 } 5 \text { 月为殖芽形 } \\
\text { 成期, } 5 \text { 月下旬至 } 6 \text { 月下旬植株大量衰败死 } \\
\text { 亡, 殖芽落人湖底等待萌发, } 7 \text { 月份生物量达 } \\
\text { 到最小值, } 8-10 \text { 月进人休眠期, } 11 \text { 月开始进 } \\
\text { 人萌发期, } 12-2 \text { 月生长速度缓慢 }{ }^{[18]} \text {. }\end{array}$ & $\begin{array}{l}1 \text { 月份最低气温低于 } 0^{\circ} \mathrm{C}, \text { 太湖湖区主要沉水植被为 } \\
\text { 伊乐藻和菹草, 伊乐藻的生物量在 } 7 \text { 月份达到最大 } \\
\text { 值, 将 } 7 \text { 月份的沉水植被图层 (伊乐藻最多) 擦除 } 1 \\
\text { 月份的沉水植被图层 (菹草和伊乐藻), 得到菹草 } \\
\text { 图层. }\end{array}$ \\
\hline 伊乐藻 & $\begin{array}{l}\text { 伊乐藻较为耐寒, 能够忍受 } 0^{\circ} \mathrm{C} \text { 以下的寒冷, } \\
5-6 \text { 月为繁殖高峰期, } 6 \text { 月下旬到 } 7 \text { 月上旬生 } \\
\text { 物量达到最大值, 之后进人休眠期, 到了 } 10 \\
\text { 月再度生长 }{ }^{[19]} \text {. }\end{array}$ & $\begin{array}{l}1 \text { 月份最低气温低于 } 0^{\circ} \mathrm{C}, \text { 太湖湖区主要沉水植被为 } \\
\text { 伊乐藻和薄草, 将 } 1 \text { 月份的沉水植被图层 (萁草和伊 } \\
\text { 乐藻) 去除菹草图层, 得到伊乐藻图层. }\end{array}$ \\
\hline 狐尾藻 & $\begin{array}{l}\text { 狐尾藻不能越冬生长, } 4-6 \text { 月为高速生长期, } \\
7 \text { 月份生物量达到最大值, } 8-9 \text { 月生长速度 } \\
\text { 减缓, } 10 \text { 月份生物量达到最小值 }{ }^{[20]} \text {. }\end{array}$ & $\begin{array}{l}10 \text { 月份沉水植被图层(狐尾藻最少)擦除 } 7 \text { 月份沉水 } \\
\text { 植被图层(狐尾藻最多), 得到狐尾藻图层. }\end{array}$ \\
\hline 微齿眼子菜 & $\begin{array}{l}\text { 微齿眼子菜不能越冬生长, } 3 \text { 月份生物量最 } \\
\text { 少, } 4-5 \text { 月份大量萌生, } 7 \text { 月份生物量达到最 } \\
\text { 大值, 随后生长减缓并逐渐向越冬期过渡 }{ }^{[21]} \text {. }\end{array}$ & $\begin{array}{l}3 \text { 月份沉水植被图层 (微齿眼子菜最少) 擦除 } 5 \text { 月份 } \\
\text { 沉水植被图层 (微齿眼子菜、伊乐藻、蕰、草、狐尾藻较 } \\
\text { 多), 得到微齿眼子菜+伊乐藻+薄草+狐尾藻图层, } \\
\text { 再去除伊乐藻、菹草和狐尾藻图层, 得到微齿眼子菜 } \\
\text { 图层. }\end{array}$ \\
\hline 金鱼藻 & $\begin{array}{l}\text { 金鱼藻不能越冬生长, } 4-5 \text { 月为缓慢生长期, } \\
6-8 \text { 月为高速生长期, } 8 \text { 月下旬到 } 9 \text { 月初生 } \\
\text { 物量最大, 随后很快消亡, } 10 \text { 月份生物量 } \\
\text { 最小 }{ }^{[22]} \text {. }\end{array}$ & $\begin{array}{l}10 \text { 月份沉水植被图层 (金鱼藻最少) 擦除 } 8 \text { 月份沉水 } \\
\text { 植被图层 (金鱼藻最多), 得到金鱼藻图层. }\end{array}$ \\
\hline 苦草 & $\begin{array}{l}\text { 苦草不能越冬生长, } 3 \text { 月进入萌芽期, } 4 \text { 月上 } \\
\text { 旬开始生长, } 7-9 \text { 月为高速生长期, } 10 \text { 月份 } \\
\text { 上旬生物量最大 }{ }^{[23]} \text {. }\end{array}$ & $\begin{array}{l}\text { 将所有月份沉水植被图层合并, 得到总的沉水植被 } \\
\text { 图层,再去除伊乐藻、蕰、狐尾藻、微齿眼子菜和金 } \\
\text { 鱼藻图层,得到苦草+马来眼子菜图层, } 10 \text { 月份下旬 } \\
\text { 的沉水植被图层 (马来眼子菜最多) 擦除苦草+马来 } \\
\text { 眼子菜图层, 得到苦草图层. }\end{array}$ \\
\hline 马来眼子菜 & $\begin{array}{l}\text { 马来眼子菜不能越冬生长, } 4-6 \text { 月为缓慢生 } \\
\text { 长期, } 7-9 \text { 月为高速生长期, } 10 \text { 月下旬生物 } \\
\text { 量最大 }{ }^{[24]} \text {. }\end{array}$ & $\begin{array}{l}\text { 苦草图层擦除苦草+马来眼子菜图层, 得到马来眼子 } \\
\text { 菜图层. }\end{array}$ \\
\hline
\end{tabular}

\section{2 结果与分析}

\section{1 水生植被类群和种群遥感监测精度验证}

利用 2017 年 7 月和 2019 年 8 月水生植被类群的实测样点数据, 通过混淆矩阵 ${ }^{[9]}$, 对 2017 年 7 月 28 日 和 2019 年 8 月 17 日两期影像的分类结果进行精度验证(表 4). 结果显示, 水生植被类群和藻华的分类总体 精度达到 $82.66 \%$, Kappa 系数为 0.77 . 其中, 挺水植被、浮叶植被、沉水植被和蓝藻水华的生产者精度分别为 $87.32 \% 、 88.75 \% 、 82.35 \%$ 和 $72.22 \%$.

利用 2017 年和 2019 年沉水植被优势种群的实测样点数据, 通过混淆矩阵 ${ }^{[9]}$, 对 2017 年和 2019 年沉水 植被优势种群分布结果进行验证 (表 5). 结果显示, 沉水植被优势种群的分类总体精度为 62.08\%, Kappa 系 数为 0.56 . 其中, 蕰草和伊乐藻的生活史和其他种群有明显的区别, 因此生产者精度最高, 分别为 $71.42 \%$ 和 $66.67 \%$; 由于微齿眼子菜与狐尾藻、马来眼子菜与苦草的生活史相似, 提取的狐尾藻与苦草图层中可能混杂 着少量微齿眼子菜与马来眼子菜, 因此微齿眼子菜和马来眼子菜的生产者精度较低, 分别为 $52.17 \%$ 和 $54.17 \%$. 
表 4 水生植被类群和蓝藻水华的分类精度

Tab.4 Accuracy assessment of classification results for aquatic vegetation types and cyanobacteria blooms

\begin{tabular}{cccccccc}
\hline 水生植被 & $\begin{array}{c}\text { 挺水 } \\
\text { 植被 }\end{array}$ & $\begin{array}{c}\text { 浮叶 } \\
\text { 植被 }\end{array}$ & $\begin{array}{c}\text { 蓝藻 } \\
\text { 水华 }\end{array}$ & $\begin{array}{c}\text { 沉水 } \\
\text { 植被 }\end{array}$ & $\begin{array}{c}\text { 生产者精度/ } \\
\%\end{array}$ & $\begin{array}{c}\text { 总体精度/ } \\
\%\end{array}$ & Kappa 系数 \\
\hline 挺水植被 & 62 & 9 & 0 & 0 & 87.32 & 82.66 & 0.77 \\
浮叶植被 & 0 & 71 & 6 & 3 & 88.75 & & 72.22 \\
蓝藻水华 & 0 & 3 & 13 & 0 & 82.35 & \\
沉水植被 & 0 & 33 & 0 & 154 & & \\
\hline
\end{tabular}

表 5 沉水植被优势种群的分类精度

Tab.5 Accuracy assessment of classification results for submerged vegetation species

\begin{tabular}{|c|c|c|c|c|c|c|c|c|c|c|}
\hline 优势种群 & 菹草 & $\begin{array}{c}\text { 伊乐 } \\
\text { 藻 }\end{array}$ & $\begin{array}{c}\text { 狐尾 } \\
\text { 藻 }\end{array}$ & $\begin{array}{c}\text { 微齿 } \\
\text { 眼子菜 }\end{array}$ & $\begin{array}{l}\text { 金鱼 } \\
\text { 藻 }\end{array}$ & 苦草 & $\begin{array}{c}\text { 马来 } \\
\text { 眼子菜 }\end{array}$ & $\begin{array}{c}\text { 生产者精度/ } \\
\%\end{array}$ & $\begin{array}{c}\text { 总体精度/ } \\
\%\end{array}$ & Kappa 系数 \\
\hline 菹草 & 20 & 4 & 2 & 0 & 1 & 1 & 0 & 71.42 & 62.08 & 0.56 \\
\hline 伊乐藻 & 5 & 20 & 3 & 0 & 2 & 0 & 0 & 66.67 & & \\
\hline 狐尾藻 & 1 & 1 & 19 & 3 & 2 & 1 & 2 & 65.51 & & \\
\hline 微齿眼子菜 & 0 & 1 & 6 & 12 & 3 & 1 & 0 & 52.17 & & \\
\hline 金鱼藻 & 2 & 2 & 0 & 3 & 16 & 2 & 2 & 59.25 & & \\
\hline 苦草 & 1 & 1 & 0 & 0 & 2 & 17 & 5 & 65.38 & & \\
\hline 马来眼子菜 & 1 & 1 & 0 & 0 & 2 & 7 & 13 & 54.17 & & \\
\hline
\end{tabular}

\section{2 围网拆除前后水生植被类群变化分析}

2017 年 (围网拆除前) 和 2019 年 (围网拆除后) 同季节水生植被类群和藻华的空间分布如图 3, 其面积 统计如表 6 ,分析结果显示: (1) 围网拆除前后, 挺水植被的面积分别为 8.29 和 $11.03 \mathrm{~km}^{2}$, 占比分别为 $4.06 \%$ 和 $5.41 \%$. 这可能是由于挺水植被集中分布在近岸边浅水区, 且芦苇对水环境有着较强的适应能力 ${ }^{[25]}$, 因此 围网拆除行为对其影响较小 (表 6). (2) 围网拆除前, 沉水植被为东太湖的优势类群, 面积约为 $32.12 \mathrm{~km}^{2}$, 占比为 $15.75 \%$; 浮叶植被面积为 $29.87 \mathrm{~km}^{2}$, 占比为 $14.65 \%$. 围网拆除后, 沉水植被分布面积减少至 21.01 $\mathrm{km}^{2}$, 占比为 $10.30 \%$; 浮叶植被分布面积增加至 $40.72 \mathrm{~km}^{2}$, 占比为 $19.97 \%$, 成为分布面积最大的水生植被优 势类群. 这可能是因为: (1)围网拆除前, 渔民为了河蟹的优质生长, 会人为补充围网中的沉水植被, 并自发地 对围网区内的浮叶植被进行打捞调控 ${ }^{[26-27]}$; 围网拆除后, 渔民不再种植沉水植被, 且不会对浮叶植被进行打 捞调控, 而浮叶植被竞争能力大于沉水植被 ${ }^{[28]}$; 2)围网拆除后, 原围网区湖泊水动力加强, 而浮叶植被抗风 浪能力比沉水植被更强 ${ }^{[29]}$. (3) 围网拆除前, 未在东太湖监测到蓝藻水华; 围网拆除后, 在太浦闸口附近水 域监测到蓝藻水华的存在, 面积为 $8.79 \mathrm{~km}^{2}$, 占比为 $4.31 \%$ (表 6). 这可能是因为: 围网养殖时期, 渔民长期 向养殖区内投放饵料和鱼药, 围网区富含营养盐的底泥沉积物剧增、水体富营养化严 ${ }^{\text {重 }}{ }^{[30]}$, 但该区域水生植 被茂盛, 抑制了蓝藻水华的暴发 ${ }^{[31]}$. 围网拆除后, 没有了围网的阻隔, 在水动力的作用下, 原围网区底泥沉 积物释放至太浦闸口附近水域,加重了该片水域的富营养化程度.

\section{3 围网拆除前后沉水植被优势种变化分析}

2017 年 (围网拆除前)和 2019 年(围网拆除后)不同月份的沉水植被空间分布如图 4, 其面积变化如图 5. 分析结果显示: 由于不同沉水植被种群的生活史不同, 沉水植被的空间分布和面积随着时间发生变化; 围 网拆除后,除 1 月份,其余月份沉水植被面积均小于围网拆除前的面积.

2017 年 (围网拆除前) 和 2019 年 (围网拆除后) 沉水植被优势种群的空间分布如图 6. 结果显示: 围网拆 除前, 除微齿眼子菜优势度较低, 分布面积占比仅为 3\%, 其它种群如菹草、伊乐藻、金鱼藻、苦草、马来眼子 菜和狐尾藻的优势度均较高, 面积占比分别为 $27 \% 、 24 \% 、 17 \% 、 10 \% 、 10 \%$ 和 $9 \%$; 围网拆除后, 除淔草、伊乐 藻与狐尾藻的优势度较高, 面积占比分别为 $47 \%$ 、22\% 和 $16 \%$, 其它种群分布面积占比之和仅为 $15 \%$. 这可 

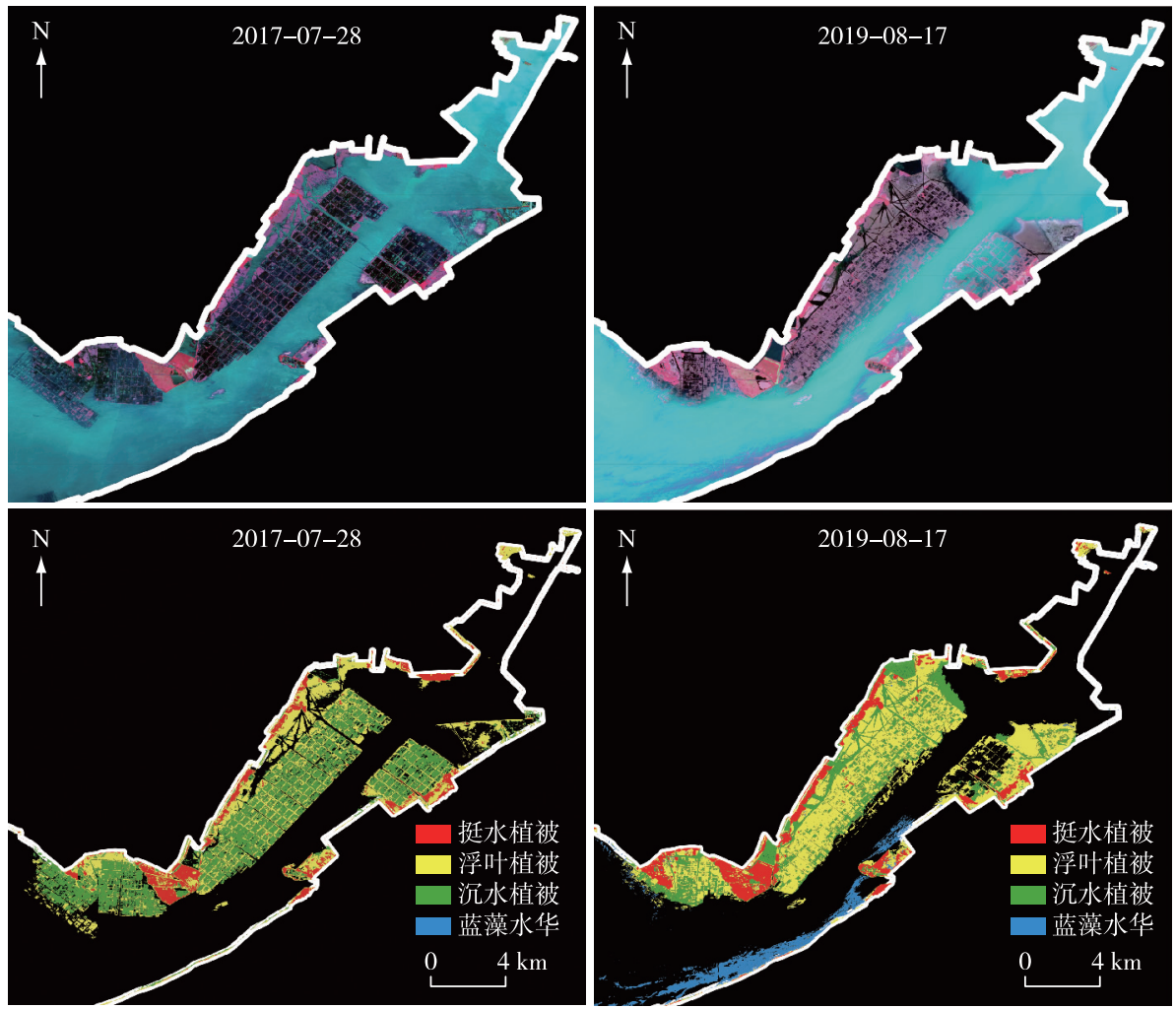

图 32017 年 (围网拆除前) 和 2019 年 (围网拆除后) 同季节水生植被类群和蓝藻水华的遥感监测图

Fig.3 Remote sensing maps of aquatic vegetation types and cyanobacteria blooms in the same season in 2017 (before pen aquaculture removal) and 2019 (after pen aquaculture removal)

能是因为: (1)围网拆除前, 水流被围网阻隔, 水动力扰动较弱; 围网拆除后, 原围网区湖泊水动力作用加强, 对苦草、金鱼藻等种群的生长产生了不利的影响 ${ }^{[22]}$. 而蕰草、伊乐藻与狐尾藻能较好的适应风浪扰动的水 动力环境 ${ }^{[33-35]}$, 因此三者的优势度较高; (2)围网拆除后, 浮叶植被在夏季大量繁殖,分布面积上升. 因此生长 时期与其相近的苦草、金鱼藻、马来眼子菜等种群优势度降低. 而菹草和伊乐藻能在冬季存活 ${ }^{[18-19]}$, 且夏季 生长的狐尾藻分布在浮叶植被较少的区域,因此三者的优势度较高.

表 62017 年 (围网拆除前) 和 2019 年 (围网拆除后) 同季节水生植被类群分类面积统计

Tab.6 Area of aquatic vegetation types in the same season in 2017 (before pen aquaculture removal) and 2019 ( after pen aquaculture removal)

\begin{tabular}{cccccc}
\hline \multirow{2}{*}{ 水生植被 } & \multicolumn{3}{c}{ 面积 $/ \mathrm{km}^{2}$} & & \multicolumn{2}{c}{ 面积占比 $/ \%$} \\
\cline { 2 - 3 } \cline { 5 - 6 } & $2017-07-28$ & $2019-08-17$ & & $2017-07-28$ & $2019-08-17$ \\
\hline 挺水植被 & 8.29 & 11.03 & & 4.06 & 5.41 \\
浮叶植被 & 29.87 & 40.72 & & 14.65 & 19.97 \\
沉水植被 & 32.12 & 21.01 & & 15.75 & 10.30 \\
蓝藻水华 & 0 & 8.79 & & 0 & 4.31 \\
\hline
\end{tabular}

\section{3 结论}

本研究基于 Sentinel-2 系列影像, 利用决策树遥感分类方法, 对东太湖围网拆除前后水生植被类群的变 

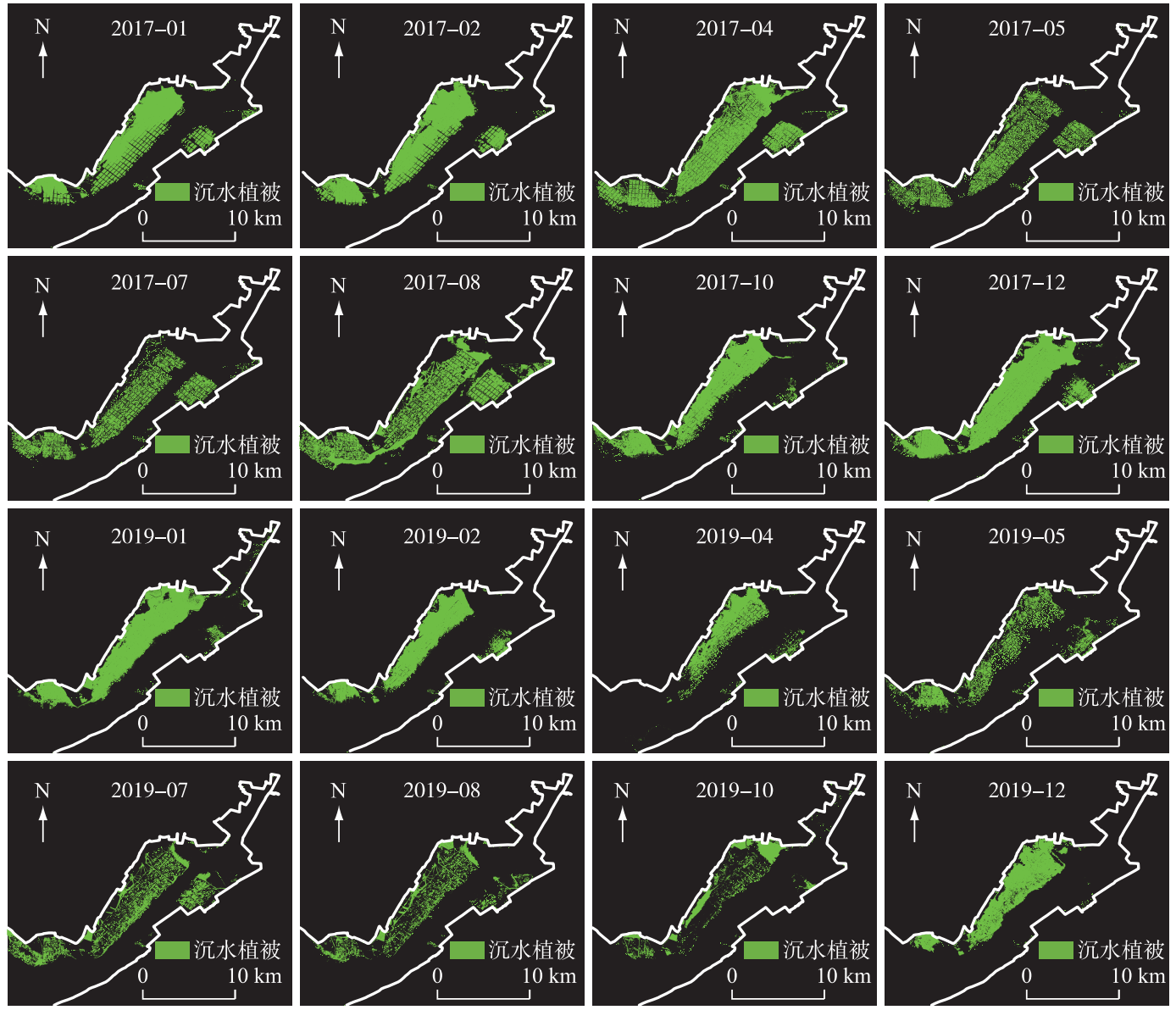

图 42017 年 (围网拆除前) 和 2019 年 (围网拆除后) 不同月份沉水植被遥感监测图

Fig.4 Remote sensing maps of submerged vegetation distribution in different months in 2017 (before pen aquaculture removal) and 2019 (after pen aquaculture removal)

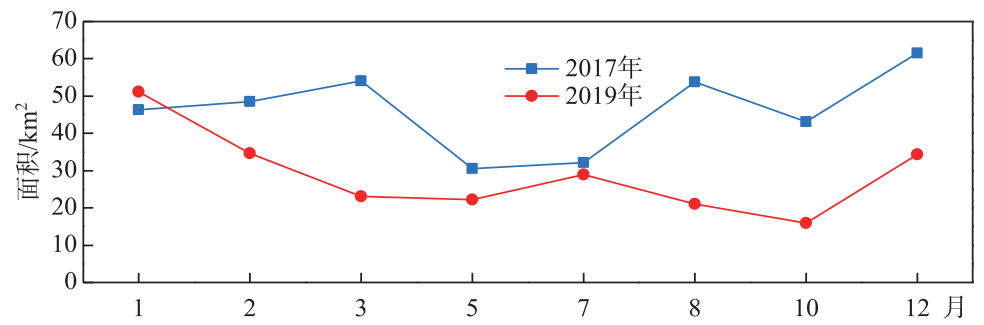

图 52017 年(围网拆除前) 和 2019 年(围网拆除后) 不同月份沉水植被面积动态变化

Fig.5 Dynamics of submerged vegetation area in different months in 2017

(before pen aquaculture removal) and 2019 (after pen aquaculture removal)

化进行了监测和变化分析, 结论为: 围网拆除后, 东太湖水生植被优势类群由围网拆除前的沉水植被转变为 浮叶植被; 同时, 结合东太湖沉水植被七大优势种群的生活史差异, 构建了沉水植被优势种群的提取方法, 对东太湖围网拆除前后沉水植被优势种群进行了监测和变化分析,结果显示: 围网拆除后,沉水植被分布面 

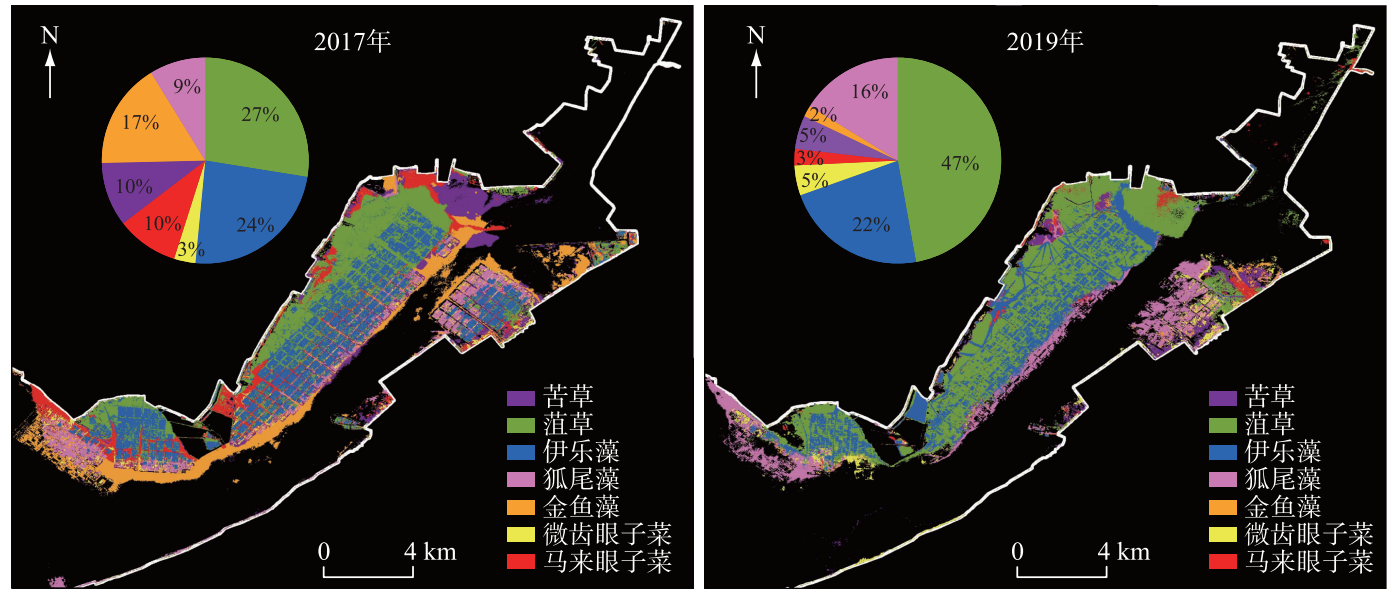

图 62017 年(围网拆除前) 和 2019 年(围网拆除后) 沉水植被优势种群分布遥感监测图

Fig.6 Remote sensing maps of submerged vegetation species in 2017 (before pen aquaculture removal) and 2019 ( after pen aquaculture removal)

积减少, 且种群由优势度相差不大的七大优势种群逐步向菹草和伊乐藻占据绝对优势发展, 逐渐趋于单一 化. 从水生植被群落生态作用的角度来看, 这种变化显示围网拆除行动对东太湖生态系统的健康发展是不 利的,但其对水质和生态系统的综合影响仍需一个更长时间才能进行全面评估

\section{4 参考文献}

[ 1 ] Wu QL. On the sustainable development of fishery in east Taihu Lake. J Lake Sci, 2001, 13(4) : 337-344. DOI: 10. 18307/2001.0408. [ 吴庆龙. 东太湖养殖渔业可持续发展的思考. 湖泊科学, 2001, 13(4) : 337-344.]

[ 2 ] Yang YB, Jiang N, Yin LQ et al. RS-based dynamic monitoring of lake area and enclosure culture in east Taihu Lake. $J$ Lake Sci, 2005, 17(2) : 133-138. DOI: 10.18307/2005.0207. [杨英宝, 江南, 殷立琼等. 东太湖湖泊面积及网围养 殖动态变化的遥感监测. 湖泊科学, 2005, 17(2) : 133-138.]

[ 3 ] Wu QL, Chen KN, Hu YH et al. Impacts of pen crab farming on evironment in east Taihu Lake. Agro-Environmental Protection, 2001, 20(6) : 432-434, 442. [吴庆龙, 陈开宁, 胡耀辉等. 东太湖河蟹网围养殖的环境效应. 农业环境保 护, 2001, 20(6): 432-434, 442.]

[ 4 ] Luo JH, Pu RL, Ma RH et al. Mapping long-term spatiotemporal dynamics of pen aquaculture in a shallow lake: Less aquaculture coming along better water quality. Remote Sensing, 2020, 12(11) : 1866. DOI: 10.3390/rs12111866.

[ 5 ] Xue JZ, Cai Z, Fang W et al. Ecological status of plankton in Kunshan area of Dianshan Lake after aquaculture net dismantling. Journal of Shanghai University, 2010, 19(4) : 514-520. [薛俊增, 蔡桢, 方伟等. 淀山湖养殖围网拆除后昆 山水域浮游生物生态现状初步研究. 上海海洋大学学报, 2010, 19(4): 514-520.]

[ 6 ] Yuan L, Wu HX, Peng ZR et al. The differences of crustacean zooplankton community structure between inside and outside of the net pen in Yangcheng Lake. Journal of Shanghai University, 2013, 22(4) : 586-592. [袁林, 吴惠仙, 彭自 然等. 阳澄湖围网内外浮游甲壳动物群落结构比较. 上海海洋大学学报, 2013, 22(4): 586-592.]

[ 7 ] Yang QX. Ecological functions of aquatic vegetation in east Taihu Lake and its reasonable regulation. J Lake Sci, 1998,10 (1) : 67-72. DOI：10.18307/1998.0111. [ 杨清心. 东太湖水生植被的生态功能及调节机制. 湖泊科学, 1998, 10 (1):67-72.]

[ 8 ] Silva TSF, Costa MPF, Melack JM et al. Remote sensing of aquatic vegetation: Theory and applications. Environmental Monitoring and Assessment, 2008, 140(1/2/3) : 131-145. DOI: 10.1007/s10661-007-9855-3.

[ 9 ] Luo JH, Li XC, Ma RH et al. Applying remote sensing techniques to monitoring seasonal and interannual changes of aquatic vegetation in Taihu Lake, China. Ecological Indicators, 2016, 60 : 503-513. DOI: 10.1016/j.ecolind.2015.07.029.

[10] Villa P, Mousivand A, Bresciani M. Aquatic vegetation indices assessment through radiative transfer modeling and linear 
mixture simulation. International Journal of Applied Earth Observation and Geoinformation, 2014, 30: 113-127. DOI: 10. 1016/j.jag.2014.01.017.

[11] Liu XH, Zhang YL, Shi K et al. Mapping aquatic vegetation in a large, shallow eutrophic lake: A frequency-based approach using multiple years of MODIS data. Remote Sensing, 2015, 7(8) : 10295-10320. DOI: 10.3390/rs70810295.

[12] Zhao DH, Lv M, Jiang H et al. Spatio-temporal variability of aquatic vegetation in Taihu lake over the past 30 years. PLoS One, 2013, 8(6) : e66365. DOI: 10.1371/journal.pone.0066365.

[13] Hu CM. A novel ocean color index to detect floating algae in the global oceans. Remote Sensing of Environment, 2009,113 (10) : 2118-2129. DOI: 10.1016/j.rse.2009.05.012.

[14] Chen HS. Urgency for protection of water environment in eastern Taihu lake. Water Resources Protection, 2000, 16(3): 17-20，45. [ 陈荷生. 东太湖水环境保护迫在眉睫. 水资源保护, 2000, 16(3): 17-20, 45.]

[15] Luo JH, Duan HT, Ma RH et al. Mapping species of submerged aquatic vegetation with multi-seasonal satellite images and considering life history information. International Journal of Applied Earth Observation and Geoinformation, 2017, 57: 154165. DOI: $10.1016 /$ j.jag.2016.11.007.

[16] Yang B, Li D, Wang L et al. Retrieval of surface vegetation biomass information and analysis of vegetation feature based on Sentinel-2A in the upper of Minjiang River. Science \& Technology Review, 2017, 35(21): 74-80. [杨斌, 李丹, 王否等. 基于 Sentine1-2A 岷江上游地表生物量反演与植被特征分析. 科技导报, 2017, 35(21): 74-80.]

[17] Shu XZ, Yin Q, Kuang DB. Relationship between algal chlorophyll concentration and spectral reflectance of inland water. Journal of Remote Sensing, 2000, 4(1) : 41-45. [ 疏小舟, 尹球, 匡定波. 内陆水体藻类叶绿素浓度与反射光谱特征 的关系. 遥感学报, $2000,4(1): 41-45$.]

[18] Hua ZL, Zhu X, Shen J et al. Response of water quality to different growth periods of Potamogeton crispus in Luoma Lake. Water Resources Protection, 2019, 35(2) : 25-31. [华祖林, 朱翔, 沈健等. 骆马湖水质对菹草不同生长期的响应研 究. 水资源保护, 2019, 35(2): 25-31.]

[19] Gu XH, Chen KN, Hu YH. Nutrient reproduction for Elodea nuttallii in east lake Taihu and its purification on of fishery sewage. Shanghai Environmental Sciences, 2002, 21(1): 43-45. [谷孝鸿, 陈开宁, 胡耀辉. 东太湖伊乐藻的营养繁 殖及对渔业污水的净化. 上海环境科学, 2002, 21(1): 43-45.]

[20] Cheng Y, Li W. Quantitative analysis on the main submerged communities in Honghu Lake. IV. Myriophyllum spicatum+ Potamogeton maackianus+Ceratophyllum demersum community. Acta Hydrobiologica Sinica, 2000, 24(3) : 257-262. [程 玉, 李伟. 洪湖主要沉水植物群落的定量分析. IV.穗花狐尾藻+微齿眼子菜+金鱼藻群落. 水生生物学报, 2000,24 (3) : 257-262.]

[21] Jin BF, Guo YH. Primary studies on the reproductive characteristics of Potamogeton maackianus. Acta Hydrobiologica Sini$c a, 2001,25(5): 439-448$. [靳宝锋, 郭友好. 微齿眼子菜繁殖生物学特性的初步研究. 水生生物学报, 2001, 25 (5) : 439-448.]

[22] Wang J, Gu YF, Zhu ZY et al. Physiological responses of Ceratophyllum demersum under different nutritional conditions. Chinese Journal of Applied Ecology, 2005, 16(2) : 337-340. [王珺, 顾宇飞, 朱增银等. 不同营养状态下金鱼藻的生 理响应. 应用生态学报, 2005, 16(2): 337-340.]

[23] Chen KN, Lan CJ, Shi LX et al. Reproductive ecology of Vallisneria natans. Journal of Plant Ecology, 2006, 30(3): 487-495. [ 陈开宁, 兰策介, 史龙新等. 苦草繁殖生态学研究. 植物生态学报, 2006, 30(3) : 487-495.]

[24] Liu WL, Hu WP, Gu XH. The biomass variation of Potamogeton malaianus and its influential factors in Lake Taihu. Acta Ecologica Sinica, 2007, 27 (8) : 3324-3333. [刘伟龙, 胡维平, 谷孝鸿. 太湖马来眼子菜 (Potamogeton malaianus) 生 物量变化及影响因素. 生态学报, 2007, 27(8):3324-3333.]

[25] Liu WL, Hu WP, Chen YG et al. Temporal and spatial variation of aquatic macrophytes in West Taihu Lake. Acta Ecologica Sinica, 2007, 27 (1): 159-170. [刘伟龙, 胡维平, 陈永根等. 西太湖水生植物时空变化. 生态学报, 2007, 27 (1) : 159-170.]

[26] Lu W, Liu X, Xu FX et al. The conservation and management of river crab pond grass. Scientific Fish Farming, 2018, (6) : 89. [陆伟, 刘旭, 徐方向等. 河蟹池塘水草的养护管理. 科学养鱼, 2018, (6) : 89.]

[27] Wang YC, Wei J. Effects of aquatic plants on the growth and water quality of river crabs. Scientific Fish Farming, 2013, (3) : 32-33. [王应超, 韦娟. 水草对河蟹生长和水质变化的影响. 科学养鱼, 2013, (3) : 32-33.]

[28] McLay CL. The distribution of duckweed Lemna perpusilla in a small southern California lake: An experimental approach. 
Ecology, 1974, 55(2) : 262-276. DOI: 10.2307/1935215.

[29] Song YZ, Zhu GW, Qin BQ. Applicability analysis of aquatic macrophytes on controlling nitrogen and phosphorus from water in the Kangshan Bay demonstration area of Lake Taihu. J Lake Sci, 2013, 25(2) : 259-265. DOI: 10.18307/2013. 0212. [ 宋玉芝, 朱广伟, 秦伯强. 太湖康山湾示范区水生植物对水体氮、磷控制的适用性分析. 湖泊科学, 2013, 25(2): 259-265.]

[30] Zhang L, Fang DD, Luo LG. Present situation and sustainable development countermeasures of lake aquatic purse-net breeding pollution. Journal of Environmental Management College of China, 2017, 27(2) : 52-55. [张否, 方丹丹, 罗来 高. 湖泊围网养殖污染现状及可持续发展对策. 中国环境管理干部学院学报, 2017, 27(2) : 52-55.]

[31] Qin BQ, Gao G, Hu WP et al. Reflections on the theory and practice of shallow lake ecosystem restoration. J Lake Sci, 2005, 17 (1) : 9-16. DOI: 10.18307/2005.0102. [秦伯强, 高光, 胡维平等. 浅水湖泊生态系统恢复的理论与实践 思考. 湖泊科学, 2005, 17(1): 9-16.]

[32] Zhu JG, Hu WP, Liu X et al. A review of the studies on the response of aquatic vegetation to hydrodynamic stress in lakes. Acta Ecologica Sinica, 2019, 39(2): 454-459. [朱金格, 胡维平, 刘金等. 湖泊水动力对水生植物分布的影响. 生 态学报, 2019, 39(2): 454-459.]

[33] Nichols SA, Shaw BH. Ecological life histories of the three aquatic nuisance plants, Myriophyllum spicatum, Potamogeton crispus and Elodea canadensis. Hydrobiologia, 1986, 131(1) : 3-21. DOI: 10.1007/BF00008319.

[34] Riis T, Biggs BJF. Hydrologic and hydraulic control of macrophyte establishment and performance in streams. Limnology and Oceanography, 2003, 48(4) : 1488-1497. DOI: 10.4319/lo.2003.48.4.1488.

[35] Yin J, Yang F, Zhang YM et al. Study on adaptability of two submerged macrophytes for wind-induced wave and high water level stress. Acta Scientiae Circumstantiae, 2018, 38(2) : 805-813. DOI: 10.13671/j.hjkxxb.2017.0389. [尹杰, 杨 飞, 张毅敏等. 两种沉水植物对风浪及持续高水位胁迫的适应性研究. 环境科学学报, 2018, 38 (2) : 805-813.] 